\title{
PERCEPÇÕES DE MUDANÇAS DO CLIMA, IMPACTOS E ADAPTAÇÃO PARA SERTANEJOS DO SEMIÁRIDO
}

\author{
SILVA, Valdenildo Pedro da- valdenildo.silva@ifrn.edu.br \\ Instituto Federal do Rio Grande do Norte / IFRN
}

\author{
FRANÇA, Gabryelle Larissa dos Santos - gabryellesantos318@gmail.com \\ Instituto Federal do Rio Grande do Norte / IFRN
}

\begin{abstract}
RESUMO: As mudanças climáticas consistem em uma preocupação mundial, tendo em vista que seus impactos podem ser irreversíveis. No Nordeste, a região semiárida, onde predomina a Caatinga, tem sofrido com as secas, ocasionadas pelo baixo regime de chuvas, que dificulta o acesso à água e impossibilita a realização de atividades agropecuárias. Tais secas podem conter fortes relações com as mudanças do clima. 0 objetivo da pesquisa foi analisar a percepção de sertanejos do Rio Grande do Norte sobre as mudanças climáticas e seus impactos, assim como as mitigações e as adaptações adotadas à convivência com a semiaridez. Para a execução do estudo, foram realizados levantamentos bibliográficos e documentais, bem como entrevistas semiestruturadas. Estas, realizadas in loco, adotaram o critério de saturação para a obtenção do número de entrevistados. Os resultados apontaram que, em virtude das alterações ambientais ocorridas na paisagem local e da escassez dos recursos hídricos, as mudanças climáticas foram percebidas por $86 \%$ dos entrevistados. A escassez dos recursos hídricos foi citada por $57 \%$ deles como a principal adversidade proveniente das referidas mudanças. Diante de tal situação, 64,3\% dos sertanejos utilizam técnicas de mitigação e de adaptação para amenizar as consequências da calamitosa convivência com a seca, sendo essas técnicas o racionamento de água, o armazenamento da água da chuva e a construção de poços artesianos. A pesquisa concluiu que a adoção dessas medidas, por envolverem questões complexas de caráter ambiental, social e econômico, é crucial para os sertanejos do semiárido do Rio Grande do Norte e apontou a necessidade de implementação de diretrizes, estratégias ou métodos ambientais mais sustentáveis que visem a reduzir os efeitos prejudiciais das mudanças climáticas.
\end{abstract}

PALAVRAS-CHAVES: Mudanças climáticas. Semiárido. Percepção. Mitigação. Adaptação.

PERCEPTIONS ON THE CLIMATE CHANGE, IMPACTS AND ADAPTATION FOR HINTERLAND RESIDENTS OF SEMIARID, BRAZIL

ABSTRACT: Climate change is a worldwide concern, since its impacts might be irreversible. In the Northeast of Brazil, the semi-arid region, where the Caatinga predominates, has suffered from droughts, caused by the low rainfall regime. This makes access to water difficult and affects the agricultural activities. Such droughts might contain strong relationships to climate changes. This research aims to analyse the perception of sertanejos (native people) from Rio Grande do Norte on the climatic changes and their impacts, as well as the mitigations and the adaptations adopted to coexistence with semiaridness. The study was carried out through bibliographical and documentary analysis and semi-structured interviews. In order to obtain the number of interviewees the criterion of saturation was used. The results revealed climate change was perceived by $86 \%$ of respondents due to the environmental changes in the local landscape and the scarcity of water resources. The scarcity of water resources was cited by $57 \%$ of the sample as the main impact resulting from these changes. In this context, $64.3 \%$ of the sertanejos used to use mitigation and adaptation techniques to reduce the consequences of the drought. These techniques related to rationing of water, storage of rainwater and the construction of artesian wells. To sum up, this research concluded that the adoption of these techniques is crucial for the semi-arid region of Rio Grande do Norte as they involve complex environmental, social and economic issues. In addition, the need to implement more sustainable guidelines, strategies or environmental methods aimed at reduce the harmful effects of climate change was highlighted. 
KEYWORDS: Climate change. Semi-arid. Perception. Mitigation. Adaptation.

\section{INTRODUÇÃO}

A problemática das mudanças do clima e de seus impactos constitui, neste limiar de século, uma questão fundante rumo à novas ações, estratégias de mitigação e adaptação (CANTERO, 2015), e um dos maiores desafios a serem enfrentados pelas sociedades atual e futura (GIDDENS, 2009). Tais alterações vêm afetando a vida de milhares de pessoas pelo mundo afora, principalmente os mais pobres, e tende a piorar através de eventos extremos como inundações e secas. Estas podem comprometer a segurança alimentar e o bem-estar humano se não forem tomadas medidas mais adequadas e construídas resiliências às mudanças do clima (IPCC, 2014; LIMANTOL et al., 2016; LÁZARO, CABECINHAS, CARVALHO, 2007; MARENGO et al., 2007; CARMO,2008). Sabe-se que as mudanças são provocadas por fenômenos naturais, como é o ciclo solar e a variação orbital. Contudo, o Painel Intergovernamental Sobre Mudanças Climáticas (IPCC, sigla em inglês para Intergovernmental Panel on Climate Change) afirma, com $90 \%$ de certeza, que as mudanças do clima atuais vêm decorrendo de atividades e ações humanas, como o desmatamento e a emissão de gases do efeito estufa, destacando-se o Dióxido de Carbono(CO2), Metano $(\mathrm{CH} 4)$ e o Óxido Nitroso (N2O), sobretudo proveniente das atividades agropecuárias e industriais, gerando consequências ambientais significativas para áreas tropicais e de altas latitudes. (IPCC, 2014).

No entanto, as preocupações com as mudanças do clima tiveram que chegar ao Fórum Econômico de Davos para que a humanidade percebesse que o aquecimento do planeta é um problema real, urgente e vital, como assinalou Leff (2010). Recentemente, elas vieram à lume na reunião do G20, realizada nos dias 7 e 8 de julho de 2017 na Alemanha, no contexto da discussão sobre meio ambiente e sustentabilidade. Mas, é importante ressaltar que essa problemática vem sendo discutida desde a $21^{\text {a }}$ Conferência das Partes (COP21), da Convenção-Quadro das Nações Unidas sobre Mudança do Clima (UNFCCC), que ocorreu em 2015 em Paris. Esse evento resultou em acordos internacionais controversos, mas a maioria dos países membros têm se comprometido a adotar medidas para a redução das emissões de gases do efeito estufa, com vistas a diminuir os impactos das mudanças climáticas.

Marengo et al. (2007) afirmam que as mudanças do clima vêm proporcionando consequências drásticas a humanidade como o aquecimento global, o derretimento das geleiras e o aumento no nível do mar. Para eles, os modelos globais sobre o clima, mesmo com nível de incertezas, projetam um futuro com possíveis mudanças climáticas extremas, com ondas de calor, de frio, chuvas intensas e enchentes, secas e ocorrência de intensos furacões e ciclones extratropicais. (MARENGO et al.,2007).

Por outro lado, Andrade et al. (2014, p.77) acrescentam dizendo que "as mudanças climáticas podem tornar mais escassos os recursos naturais das regiões semiáridas do planeta prejudicando as populações agrícolas que dependem de sua qualidade".

Além disso, não se pode esquecer dos inúmeros alertas que vêm sendo dados pelo IPCC sobre as mudanças do clima e seus impactos ambientais. Esse órgão, formado pela Organização das Nações Unidas (ONU) e pela Organização 
Meteorológica Mundial (OMM) e o Programa das Nações Unidas para o Meio Ambiente (PNUMA), reúne cientistas de todo o mundo, que tem feito avaliações periódicas sobre as mudanças climáticas, publicadas em relatórios desde os anos de 1990, 1995, 2001, 2007 e 2014 (disponibilizados no www.ipcc.br), constituindo, também, nas principais referências sobre a temática no mundo inteiro.

No seu quinto e último relatório de avaliação de 2014, o IPCC forneceu uma síntese geral do estado dos conhecimentos sobre a ciência das mudanças climáticas, ressaltando novos resultados em relação aos informes dos anos anteriores. Destacou-se no documento de 2014, as preocupações com a interferência humana no sistema climático, devido aos sérios riscos que a mesma traz para os sistemas naturais e humanos.

A preocupação central dos últimos relatórios do IPCC tem recaído sobre a elevação da temperatura causada pelas atividades humanas (CARMO, 2008; IPCC, 2014), mas, também, tem considerado que os impactos e riscos relacionados às mudanças do clima podem ser reduzidos e gerenciados por meio de diversas e distintas ações e atividades de adaptação e mitigação.

No último relatório, observou-se a preocupação em avaliar as necessidades, opções, oportunidades, barreiras, resiliência, limites e outros aspectos associados à adaptação. A mudança climática envolve interações complexas entre o homem e a natureza, e mudanças através da manutenção de diversos impactos, que podem ser percebidas por indivíduos e sociedades, os quais classificam como riscos e benefícios de maneiras distintas, dado os diferentes valores e objetivos de cada ser humano em seu ambiente vivencial (IPCC, 2014). Contudo, as pesquisas sobre mudanças do clima têm sido, principalmente, resultantes de modelos matemáticos e de elaboração de cenários que não levam em consideração expectativas, anseios, satisfações e insatisfações, julgamentos e condutas de pessoas em relação aos seus meios vivenciais, onde as agruras e as vulnerabilidades são mais percebidas e sentidas na ótica dos que vivenciam as mudanças do clima.

Nesse contexto, a percepção sobre impactos às mudanças do clima torna-se relevante e atual, devendo ser compreendida como sendo a tomada de consciência dos problemas advindos das alterações climáticas pelos seres humanos, em especial os sertanejos que habitam o semiárido brasileiro, ou melhor, da visão que o homem do sertão tem do ambiente em que vive em relação as mudanças do clima atuais e as estratégias para mitigação e adaptação por eles adotadas, visando a diminuir ou a evitar danos futuros (OLIVEIRA, 2001; SILVA, 2016).

A percepção das mudanças do clima e de seus impactos pode ser compreendida, ainda, na visão de Rosa e Silva (2002), como sendo as maneiras com que indivíduos veem, compreendem e se comunicam com o seu ambiente de vivência, considerando-se as influências ideológicas de cada sociedade. Ou melhor dizendo, a percepção ambiental sobre as mudanças do clima, a partir da concepção daqueles que vivem e labutam no semiárido, torna-se atual, devido as consequências agudas e irreversíveis das mudanças climáticas, como a última grande seca e a vulnerabilidade de acesso a água que vêm ocorrendo de forma mais intensa de 2012 até os dias atuais. As percepções ambientais podem contribuir com estratégias que podem amenizar os problemas socioambientais, assegurando opiniões e participação social ou o envolvimento de todos os 
distintos atores nos processos de gestão ambiental (VASCO; ZAKRZEVSKI, 2010). Esses processos são compreendidos como um conjunto de diretrizes, medidas ou procedimentos bem definidos e adequadamente aplicados que visam reduzir e controlar impactos ambientais sobre o meio ambiente ou danos ou problemas resultantes de ações humanas, como é o caso específico do aquecimento local e global e das mudanças do clima contemporâneas (VALLE,1995; BARBIERI, 2007).

O bioma da Caatinga é o que mais têm sofrido com as mudanças climáticas, pois as consequências das mudanças do clima parecem já confirmar as previsões do IPCC, resultando, nos últimos anos, no aumento da temperatura, baixo índice pluviométrico e elevado índice de aridez nas áreas geográficas do semiárido do Nordeste do Brasil (INSA,2013).

Esse recorte espacial brasileiro é atualmente composto por 1.135 municípios ${ }^{1}$ presentes em nove estados do Nordeste e, também, em alguns municípios do norte de Minas Gerais e noroeste do Espírito Santo (BRASIL, 2005), ocupando $969.589,4 \mathrm{Km}^{2}$ (15,9 \% do território brasileiro), onde vivem cerca de 32 milhões de pessoas (IBGE, 2017).

Entre os estados do Nordeste, o Rio Grande do Norte tem se destacado, devido possuir a maior área dimensional de semiaridez. pois possui cerca de 93,4\% de seu território afetado pelo avassalador processo de desertificação, que pode ter origem ecológica, através da variabilidade climática ou por perturbações antrópicas, como a degradação do solo e da cobertura vegetal, o manejo inadequado do solo e queimadas. Dos 167 municípios existentes no Estado, 147 deles integram o semiárido do Rio Grande do Norte (INSA, 2013).

No entanto, pouco se sabe ou se têm conhecimentos científicos sobre as mudanças do clima na ótica do homem sertanejo do semiárido. Os conhecimentos produzidos sobre o fenômeno das mudanças climáticas, no geral, originam-se de modelos computacionais de modelagem climáticas apuradas e de construção de cenários e muito pouco da visão de indivíduos e pessoas. Diante do exposto, foram formuladas as seguintes indagações de estudo: que percepções ambientais são expressas de moradores do semiárido do Rio Grande do Norte sobre as mudanças climáticas atuais? Quais impactos ambientais são sentidos pelos sertanejos e que estão vinculados às mudanças do clima? Que estratégias de mitigação e de adaptação têm sido percebidas e propostas por sertanejos norte-rio-grandense para se conviver com as adversidades das mudanças do clima?

Portanto, a presente pesquisa objetivou conhecer a percepção de sertanejos do Rio Grande do Norte sobre mudanças climáticas e impactos, assim como as mitigações e adaptações à convivência com o Semiárido, visando o desenvolvimento sustentável da região.

\section{MATERIAL E MÉTODOS}

\footnotetext{
${ }^{1}$ Contudo, encontra-se em tramitação no Ministério da Integração Nacional uma nova delimitação, na qual mais 54 municípios passarão a compor a região semiárida do Brasil, sendo 36 no Piauí, 15 no Ceará e três na Bahia, totalizando 1.189. Essa proposta de inclusão de municípios ao semiárido brasileiro foi apresentada pelo ministro da Integração Nacional, Helder Barbalho, no dia 27 de julho de 2017, em Recife, durante reunião do Conselho Deliberativo (CONDEL) da Superintendência do Desenvolvimento do Nordeste (BRASIL, 2017).
} 
O estudo caracteriza-se, no que se refere à natureza da pesquisa, como sendo exploratório, devido possibilitar a obtenção de novas percepções ou uma aproximação a novas ideias (GIL, 2008; CERVO; BERVIAN, 2002) decorrentes dos efeitos das mudanças do clima na visão de seres humanos mais afetados e vulneráveis. Para tanto, a pesquisa envolveu levantamentos documental e bibliográfico pertinentes à discussão e coleta de dados secundários sobre a realidade de alguns municípios do Semiárido Potiguar mais afetados pelo processo de desertificação. Acrescenta-se, ainda, a aplicação de um instrumento de entrevista, contendo questões abertas e fechadas (Ver quadro 1), junto a moradores mais antigos e residentes nos municípios pesquisados.

Além da pesquisa exploratória, pode-se afirmar que o estudo se caracterizou, no que diz respeito aos seus objetivos, como uma pesquisa descritiva, já que os resultados do estudo, em quase sua plenitude, se embasaram em dados ou fatos obtidos da própria realidade social investigada (CERVO; BERVIAN, 2002; GIL, 2008): pessoas e municípios do semiárido norterio-grandense. Esse tipo de pesquisa possibilita a descrição das características dos sujeitos e do fenômeno em investigação.

A pesquisa foi realizada nos municípios de Bom Jesus, Senador Elói de Souza, Sítio Novo, Tangará, Santa Cruz, Lajes Pintadas, Currais Novos, Acari e Cruzeta localizados geograficamente nas microrregiões Borborema Potiguar e Seridó Oriental do Estado do Rio Grande do Norte, como podem ser observados na Figura 1.

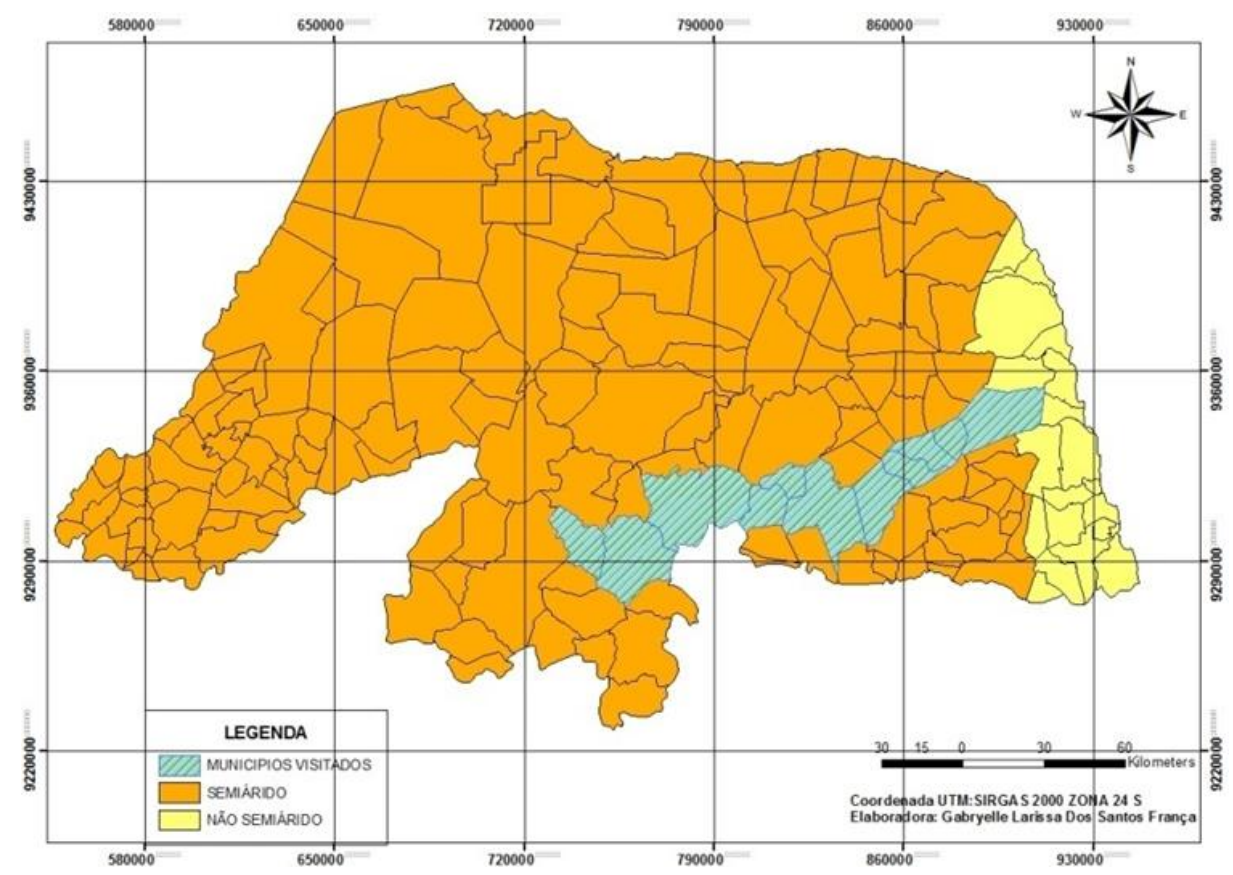

Figura 1 - Área geográfica do semiárido do Estado do Rio Grande do Norte Fonte: Núcleo de Estudo do Semiárido (2017).

Essa é área do semiárido norte-rio-grandense que tem sido bastante afetada por mudanças climáticas, principalmente pela escassez de água e pelas 
secas que têm se intensificado desde o ano de 2012 até os dias atuais, e onde os rigores delas têm sido mais drásticos e avassaladores. A altitude média dos municípios pesquisados é de aproximadamente 220 metros acima do nível do mar, nos quais as precipitações pluviométricas médias anuais ficaram abaixo de 330 milímetros (bem inferior ao que preconiza a nova delimitação do semiárido brasileiro que é $800 \mathrm{~mm}$ ) entre os anos de 2012 a 2017. A situação climática atual não tem sido resultante somente da falta de chuvas, mas da sua má distribuição, associada a altas temperaturas (médias anuais de cerca de $\left.27,6^{\circ} \mathrm{C}\right)$, elevada taxa de evapotranspiração, baixa umidade relativa do ar (entorno de 68,3\%) que resultam no fenômeno da seca. Acrescente-se, ainda, que nessa área geográfica o índice de aridez é de até 0,5 , calculado pela razão das precipitações e da evapotranspiração potencial, além de apresentar riscos de seca maior que 60\% (RIO GRANDE DO NORTE, 2017; BRASIL, 2005).

Optando-se por uma abordagem qualitativa de investigação, o universo das pessoas entrevistadas foi definido a partir do "critério de saturação" que, segundo Sá (1998), costuma ser usado para se chegar a um dado número de inquiridos (não definido a priori) no desenrolar da investigação. Para o autor, quando os argumentos e/ou temas da entrevista começam a se repetir aumentar o número de sujeitos entrevistado pouco acrescentaria de significativo a pesquisa, podendo realizar mais algumas entrevistas e em seguida parar. Portanto, foram entrevistados moradores de municípios do semiárido do Rio Grande do Norte, selecionados aleatoriamente. A amostragem não se baseou em critério numérico para garantir sua representatividade, já que uma amostra boa, numa pesquisa qualitativa, é aquela que abrange a totalidade e a vivência com o problema investigado em suas múltiplas dimensões, embasando-se nas palavras de Minayo (1992).

A entrevista foi adotada pelo estudo, devido ser um método considerado flexível, informal e umas das formas mais adequadas para se obter informações a respeito da percepção das pessoas. Além de que, para Kidder (1987), ela quase sempre produz uma melhor amostra da população em estudo.

A busca por sentimentos e opiniões sobre as mudanças climáticas e seus efeitos no semiárido do Rio Grande do Norte foi realizada por meio de uma entrevista aplicada de forma aleatória no dia 20 de fevereiro de 2017. A aplicação contou com a participação de dois pesquisadores e três estudantesbolsistas (como voluntários ao estudo), do Núcleo de Estudos do Semiárido (NESA), pertencente ao Instituto Federal do Rio Grande do Norte.

Os aspectos éticos constituíram-se em uma preocupação permanente durante a realização da entrevista e a produção deste artigo, seguindo diretrizes e normas da Resolução CNS n. 466/12 (BRASIL, 2012), salvaguardando o anonimato do participante-entrevistado (designado neste texto pela palavra morador e por algarismos arábicos $-1,2,3, \ldots$ ), mas sobretudo a dignidade, os direitos, a segurança e o bem-estar dos participantes desta pesquisa.

O instrumento de entrevista foi subdivido entre em três itens: identificação de impactos ambientais causados pelas mudanças climáticas; mudança climática e impactos afetando a vida dos sertanejos; e adaptação e mitigação às mudanças climáticas, como podem ser vistas no quadro 1.

Quadro 1-Instrumento de entrevista. Fonte: Autoria própria (2017). 


\begin{tabular}{|c|c|}
\hline $\begin{array}{c}\text { Item } 1 \text { - Identificar os } \\
\text { impactos ambientais causados } \\
\text { pela mudança climática }\end{array}$ & $\begin{array}{l}\text { 1- O clima daqui mudou? ( ) Sim () } \\
\text { Não ( ) Outra/ Não se aplica } \\
\text { 2- A partir de quando e como você } \\
\text { percebeu que o clima mudou? } \\
\text { 3- Você sabe o que é impacto } \\
\text { ambiental? ( ) Sim ( ) Não ( ) } \\
\text { Outra/ Não se aplica }\end{array}$ \\
\hline $\begin{array}{l}\text { Item } 2 \text { - Como a mudança } \\
\text { climática e os impactos ambientais } \\
\text { afetou a vida dos sertanejos }\end{array}$ & $\begin{array}{l}\text { 1- As mudanças do clima afetaram } \\
\text { sua vida? ( ) Sim ( ) Não ( ) } \\
\text { Outra/ Não se aplica. Como? }\end{array}$ \\
\hline $\begin{array}{c}\text { Item } 3 \text { - Adaptação e mitigação } \\
\text { dos impactos ambientais e as } \\
\text { mudanças climáticas }\end{array}$ & $\begin{array}{l}\text { 1- O que você tem feito para } \\
\text { diminuir as consequências da } \\
\text { seca dos últimos cinco anos? } \\
\text { 2- Existem ações do poder público } \\
\text { para minimizar os impactos } \\
\text { ambientais das mudanças do } \\
\text { clima? ( ) Sim ( ) Não ( ) } \\
\text { Outra/ Não se aplica. Quais são } \\
\text { as ações? }\end{array}$ \\
\hline
\end{tabular}

Após a realização das entrevistas, os dados foram tratados e analisados, considerando-se aspectos da análise de conteúdo (originados das falas/textos e contextos dos sujeitos da pesquisa), embasando-se nas perspectivas de Bardin (2002) e Patton (2002).

\section{RESULTADOS E DISCUSSÃO}

A análise preliminar dos dados obtidos, a partir da aplicação das entrevistas com 28 sertanejos do semiárido norte-rio-grandense, revelou que $61 \%$ dos entrevistados eram do sexo feminino e $39 \%$ dos entrevistados eram do sexo masculino. A idade dos entrevistados variou de 18 a 95 anos, sendo a maior frequência de idade no intervalo de 44 a 56 anos $(28,6 \%)$, seguido pela faixa de 31 a 43 anos (21,4\%), 18 a 30 anos e 57 a 69 anos ambos apresentaram a mesma porcentagem (17,9\%), 70 a 82 anos $(10,7 \%)$ e $83 a 95$ anos $(3,6 \%)$. Essa heterogeneidade nas idades dos entrevistados, foi importante para conhecer diferentes percepções em relação as alterações sofridas pelo ambiente em decorrência das mudanças climáticas.

A respeito da escolaridade dos inquiridos pela pesquisa, compreende maiores percentuais para ensino fundamental (32\%), seguido de não alfabetizados e ensino médio, ambos apresentaram o mesmo percentual $(25 \%)$ e parte dos entrevistados optaram por não informar a escolaridade (18\%), como pode ser observado na figura 2. 
não alfabetizado $\square$ Ensino fundamental $\square$ Ensino médio $\square$ Não informou

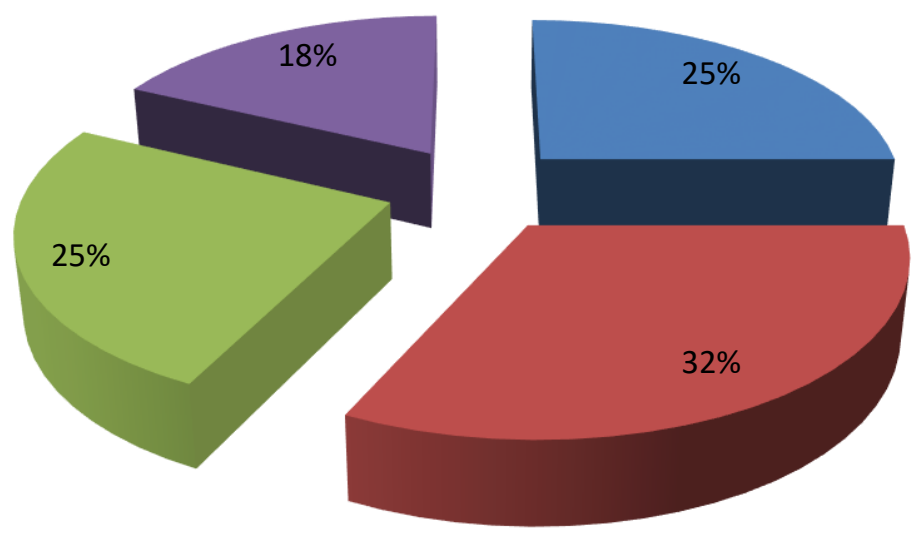

Figura 2 -Percentual de entrevistados segundo o grau de escolaridade. Fonte: Pesquisa de campo (2017).

Quando indagados sobre o conhecimento a respeito da existência de impactos ambientais, $47 \%$ dos entrevistados afirmaram não saber o que seria impacto ambiental, apenas 39\% responderam saber o que é impacto ambiental e $14 \%$ preferiram não responder. "O conhecimento e o nível de informação sobre temas ambientais são influenciados pelas características sociodemográficas das pessoas" (SECTMA, 2003, p. 9). Mesmo diante de um percentual elevado de pessoas que desconheciam o que era um impacto ambiental, ouvimos dos que disseram saber o que significa a seguinte afirmação: "impacto ambiental é qualquer ação que degrade o meio ambiente". Nesse aspecto, parece existir uma enorme preocupação de quase de todos os moradores que têm sido afetados pelas secas constantes, pelas altas temperaturas e, principalmente, pela escassez de água. Esse tem sido um dos maiores problemas percebidos por todos os entrevistados.

Quando perguntados sobre o tempo de residência na região semiárida, $21,4 \%$ entrevistados afirmaram morar na região desde que nasceram, seguido de $17,9 \%$ entrevistados que afirmaram residir na região entre 21 a 30 anos e 31 a 40 anos respectivamente, os entrevistados que residem de 11 a 20 anos totalizaram $14,3 \%$, e de 1 a 10 anos forma 10,7\% entrevistados, já 7,1\% moradores afirmaram residir de 51 a 60 anos, 7,1\% entrevistados não souberam responder, 3,6\% morador reside a 61 a 70 anos e nenhum dos entrevistados reside na região entre 41 e 50 anos, como apresenta a figura 3. Através da análise desses dados foi possível identificar que os sertanejos que residem a mais tempo na região presenciaram e são capazes de descrever com mais nitidez de detalhes as transformações sofridas pelo ambiente em virtude das mudanças climáticas. 


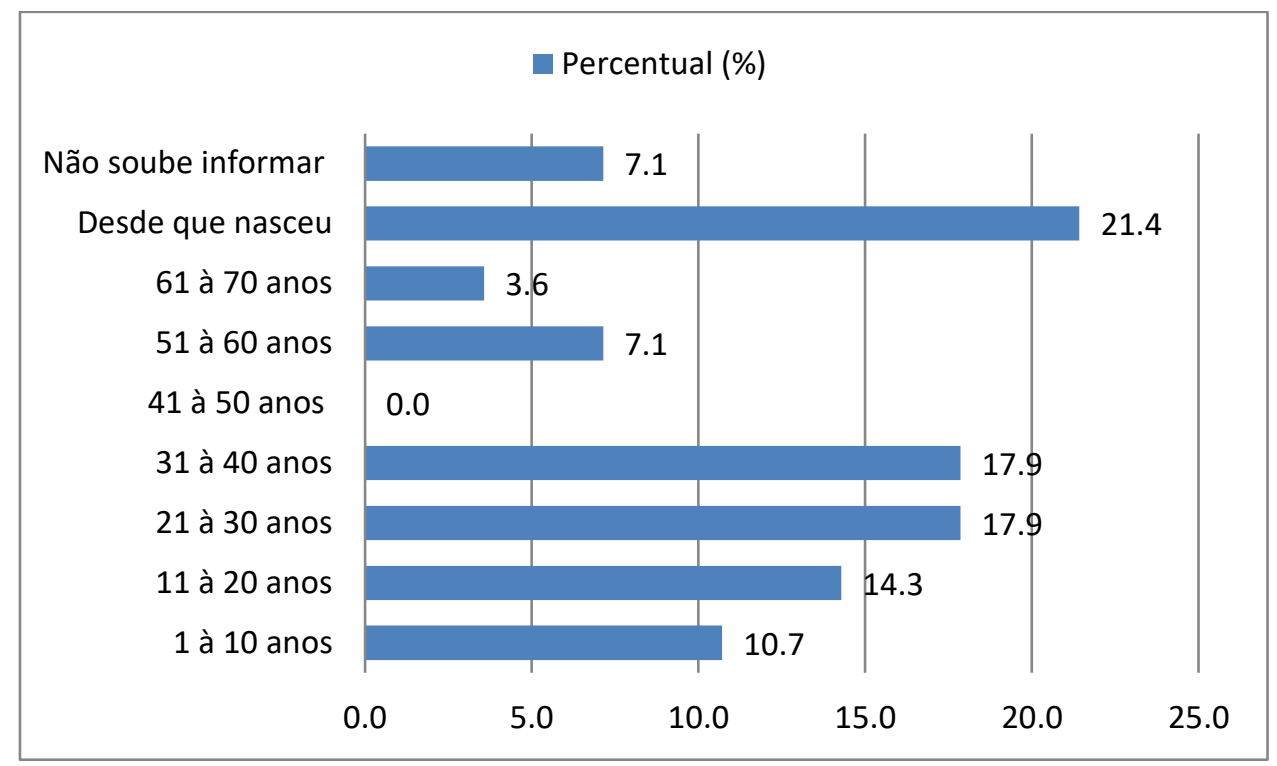

Figura 3 - Percentual do tempo de residência na região semiárida. Fonte: Pesquisa de campo (2017).

No tocante a indagação sobre a mudança do clima no local de moradia do entrevistado, as respostas foram as seguintes: 24 (86\%) responderam que sim, enquanto que $4(14 \%)$ afirmaram negativamente, expressando que nenhuma mudança tem surgido na localidade.

Os 24 entrevistados que afirmaram que houve mudanças no clima local, que podem ter origem nas mudanças climáticas globais. Já em relação ao período no qual essas mudanças climáticas tiveram início, 39,3\% entrevistados afirmaram que as mudanças começaram entre 4 e 6 anos, seguido de $21,4 \%$, moradores que não souberam informar, $14,3 \%$ afirmaram que as mudanças começaram a acontecer entre 1 e 3 anos, para 10,7\% entrevistados 0 questionamento não se aplicou, $7,1 \%$ entrevistados responderam ser mais de 12 anos entre 7 e 9 anos, e apenas 3,6\% entrevistado afirmou ser entre 10 e 12 anos. Conforme apresenta a figura 4. 


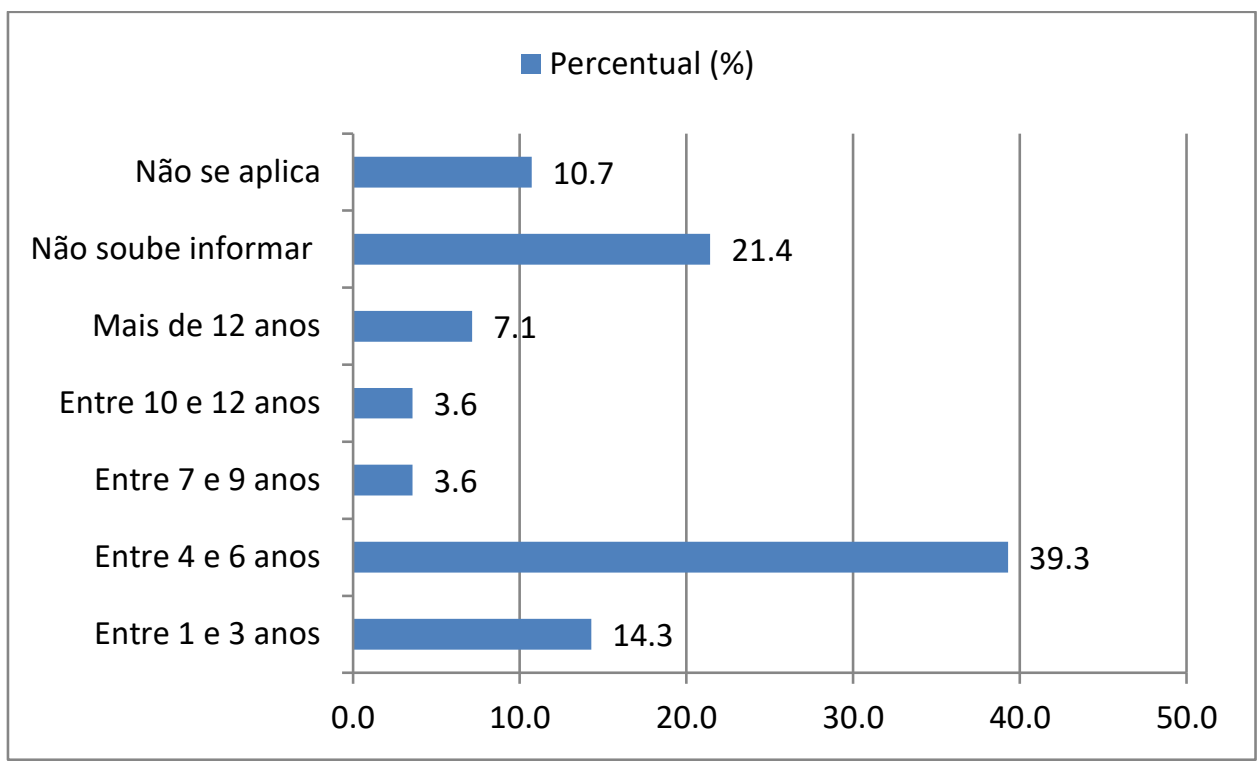

Figura 4 -Início das mudanças climáticas. Fonte: Pesquisa de campo (2017).

No tocante aos impactos provocados pelas mudanças climáticas, $78 \%$ entrevistados responderam que as mudanças climáticas trouxeram consequências nas suas atividades cotidianas, $18 \%$ responderam que às mudanças climáticas não afetaram o cotidiano e em apenas $4 \%$ esse quesito não se aplicou, pois nesse caso o morador afirmou que o clima da região não sofreu alterações. Diante das respostas dos sertanejos entrevistados, para esse quesito, foi possível inferir que, os moradores que perceberam as mudanças climáticas foram àquelas que possuem maior tempo de moradia no município, pois essas pessoas puderam presenciar as alterações e sentir os impactos sobre as suas atividades cotidianas, e podem comparar a realidade atual com a realidade vivida a mais de 6 anos atrás, período onde as mudanças climáticas se intensificaram. Foi constatado, também, que os sertanejos que afirmaram que os impactos provocados pelas mudanças climáticas afetaram suas atividades cotidianas, tem como principal fonte de renda a agricultura, atividade esta que se tornou totalmente inviável devido à seca e ao aumento da temperatura.

De acordo os entrevistados, a escassez de água constitui o principal impacto provocado pela mudança climática. Os outros impactos citados foram a agricultura, a seca, a pecuária, renda familiar, altas temperaturas, emprego, pesca e comércio, respectivamente. Maior parte dos impactos citados pelos entrevistados estão diretamente ligados ao principal problema enfrentado por eles, a escassez de água, sendo assim conhecer as medidas que adotadas por eles para minimizar as consequências da seca e se adaptarem a ela, como podemos observar na figura 5 gerada pela ferramenta Wordle. 


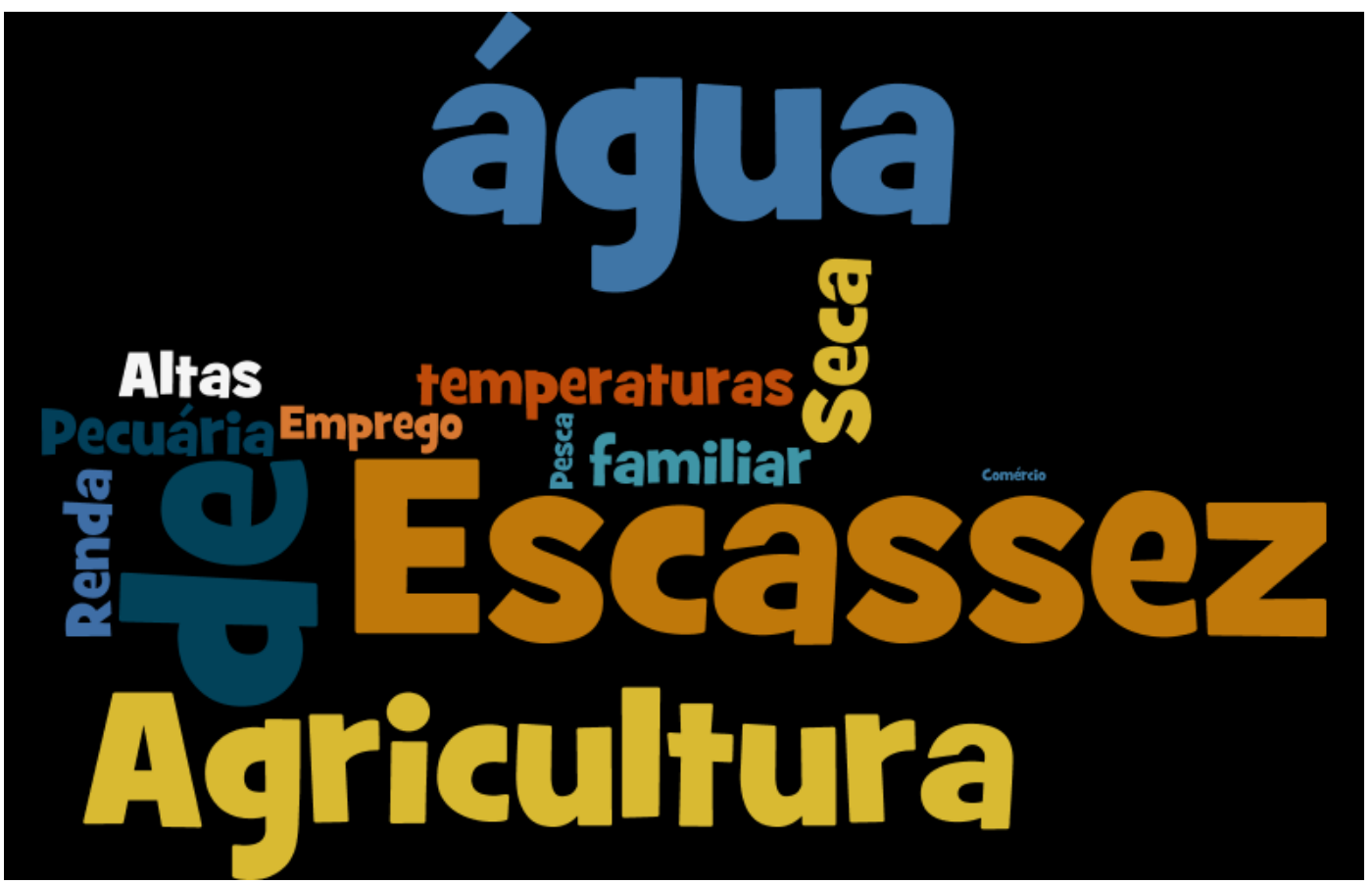

Figura 5 - Impactos provocados pelas mudanças climáticas. Fonte: Pesquisa de campo (2017).

Em entrevista os moradores relataram a dificuldade de morar na região semiárida e como a escassez de água tornou ainda mais árdua à rotina do sertanejo.

"Eu moro aqui faz cinco anos, o clima aqui é a quentura que é grande demais, porque não chove desde que eu vim pra cá praticamente que as chuvas são muito poucas. Isso afetou a vida da gente tudinho, porque a gente não tem água é uma luta um sacrifício pra gente ter água aqui, agora que a prefeitura tá mandando abastecer aqui, mas coloca uma carrada d'água pra três famílias, que num estante se acaba também a água, mas a gente tem que agradecer a Deus, primeiramente porque sem água a gente não sobrevive. A falta d'água é um impacto ambiental. Choveu pouco aqui esses dias, mas deu pra molhar um pouquinho aqui. A água que tem aqui é a prefeitura que traz do açude dourado. A gente tem que se virar do jeito que pode, porque água pra beber eles colocam lá na escola pra gente pegar, ai quando não posso pegar água lá, quando tenho dinheiro eu compro, quando não tenho dinheiro tenho que esperar alguém pra me ajudar" (Trecho da entrevista realizada no dia 20/02/2017 com o morador 10). 
Em relação a agricultura e a pesca alguns entrevistados fizeram os seguintes relatos:

"Essa seca prejudicou muita a nossa vida, pois nós somos pescadores, dependemos da pesca, afetou muito nosso emprego". (Trecho da entrevista realizada no dia 20/02/2017, morador 15).

"Essa mudança no clima não me afetou, mais afetou quem trabalha com a agricultura, que falta água, não chove, falta água". (Trecho da entrevista realizada no dia 20/02/2017, morador 11).

"Essa mudança afetou a nossa vida principalmente pela falta de água e a falta de chuva. Essas mudanças afetou a maioria das pessoas que moram aqui, pois é uma vila de pescadores e não tem como pescar". (Trecho da entrevista realizada no dia 20/02/2017, morador 26).

Diante da problemática da escassez de água levantada pelos moradores entrevistados, tornou-se de extrema importância conhecer as medidas adotadas por eles para minimizar as consequências da seca e se adaptarem a ela. Os resultados obtidos foram os seguintes: $50 \%$ da amostra faz apenas racionamento de água, $17,9 \%$ não fazem nada para minimizar os impactos da seca, outros $17,9 \%$ não souberam informar, $7,1 \%$ fazem racionamento de água e constroem poços e cisternas, 3,6\%apenas armazena água da chuva e outros $3,6 \%$ racionam água e armazenam água da chuva, como é possível visualizar na figura 6 . No que diz respeito as medidas adotadas para minimizar os impactos da escassez de água, é considerado alto o percentual de sertanejos que não fazem nada, tendo em vista que as medidas adotadas por outros sertanejos são consideradas simples e tem contribuído para adaptação da população do semiárido. 


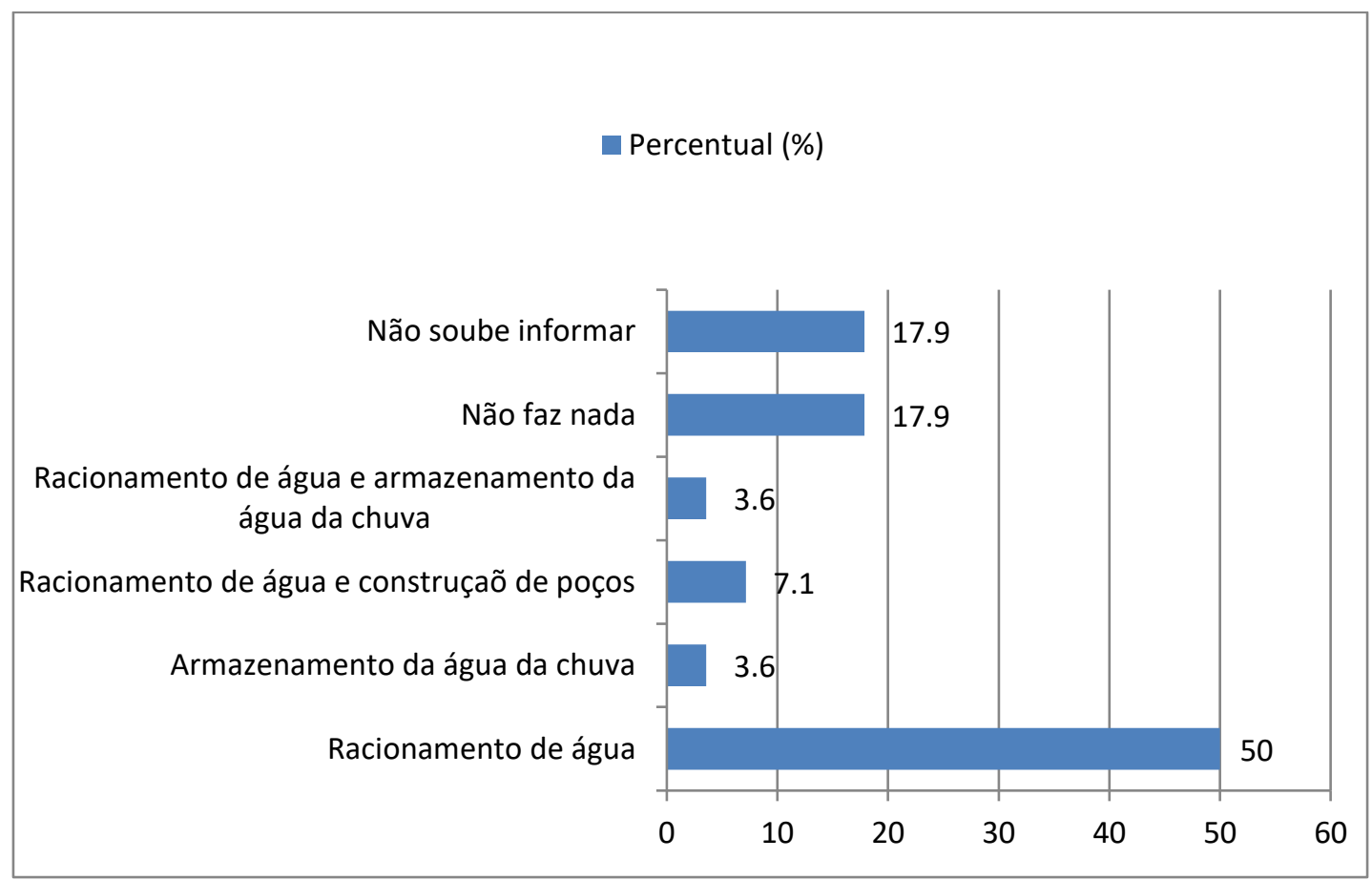

Figura 6 - Medidas adotadas para minimizar as consequências da seca. Fonte: Pesquisa de campo (2017).

Alguns entrevistados ressaltaram a importância de alguns programas do governo, tais como a construção de cisternas, a abertura de poços e a distribuição de água por carros pipa, que facilitaram o acesso à água, principalmente durante a seca dos açudes. Nas palavras de um deles,

"O governo trouxe para cá um programa de cisternas e carro pipa, quando o açude estava no volume morte funcionou o carro pipa. Ele vinha em uns dias e abasteciam os chafarizes, e toda a população daqui era beneficiada. Hoje o açude não está mais no volume morto porque choveram esses dias, então a água que a gente está usando vem dele hoje". (Trecho da entrevista realizada no dia 20/02/2017 com o morador 26).

Para outro entrevistado,

"A água aqui, a gente passou por um período muito ruim, porque o açude secou, a gente foi abastecida por pipa, mas aí no início do ano passado deu uma chuva, entrou uma aguinha, é com o que a gente está sobrevivendo até hoje, a gente recebe a água do Açude Gargalheiras". (Trecho da entrevista realizada no dia 20/02/2017 com o morador 15). 
Durante a pesquisa de campo foi possível observar alterações na paisagem do semiárido, através da instalação de chafarizes, cisternas e poços. Também foi possível observar a presença de carros pipas, realizando o abastecimento das residências, constituindo em estratégias de adaptação às mudanças do clima, visando amenizar os impactos provocados pela escassez de água como pode ser observado pelas Figuras 7, 8 e 9.

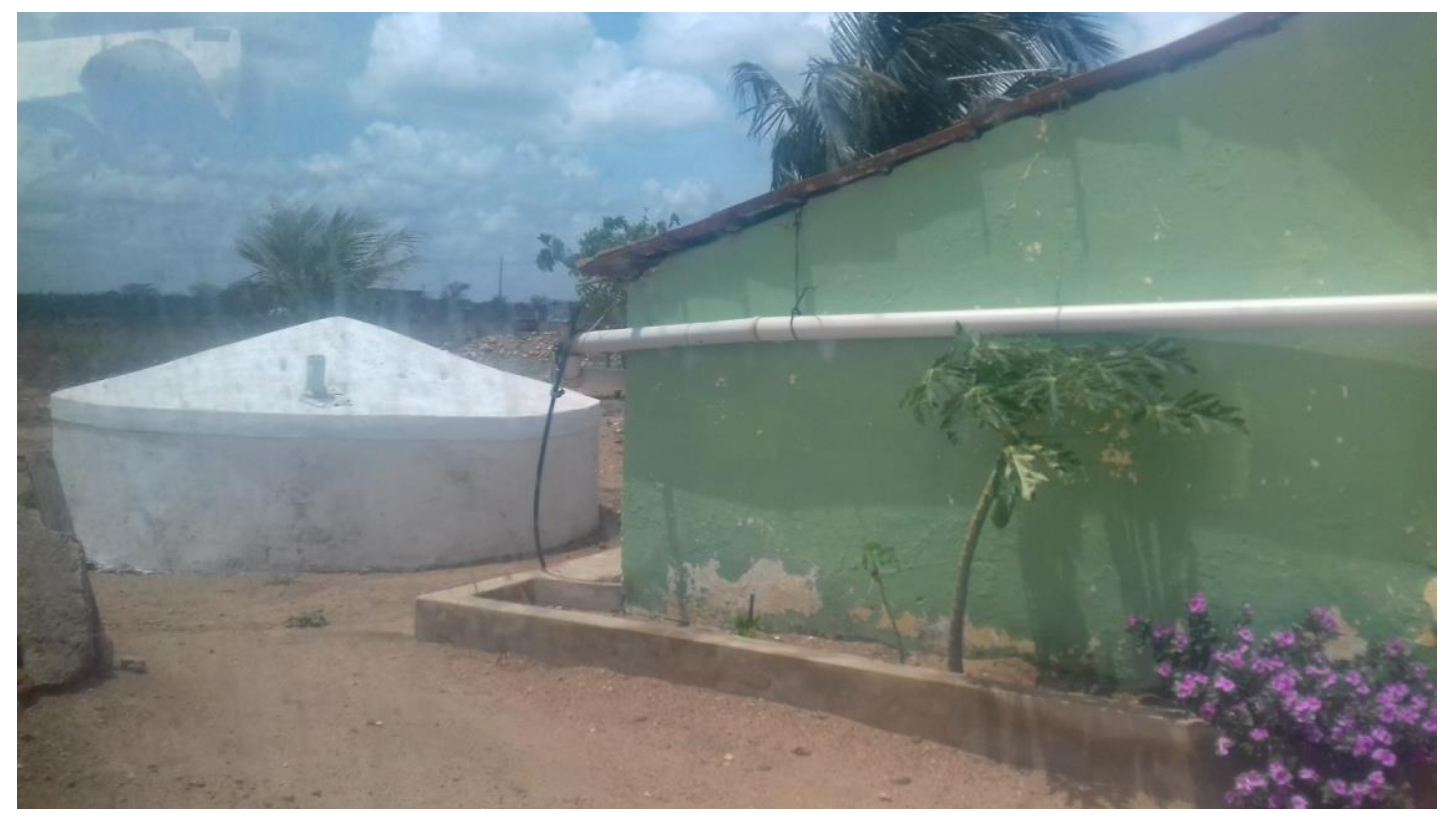

Figura 7 - Cisterna no município de Acari. Fonte: Pesquisa de campo (2017). 


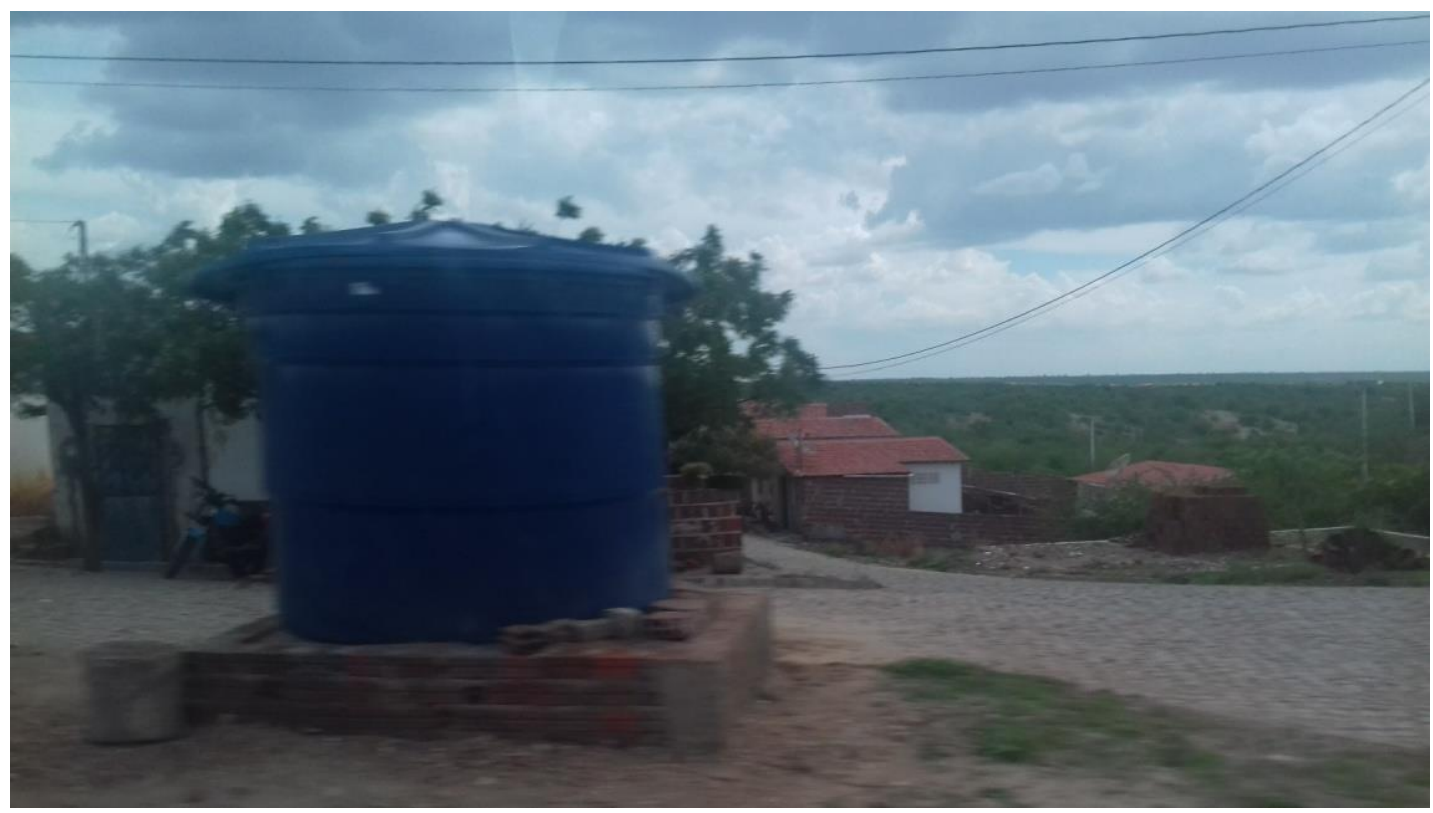

Figura 8-Chafariz no município de Cruzeta.Fonte: Pesquisa de campo (2017).

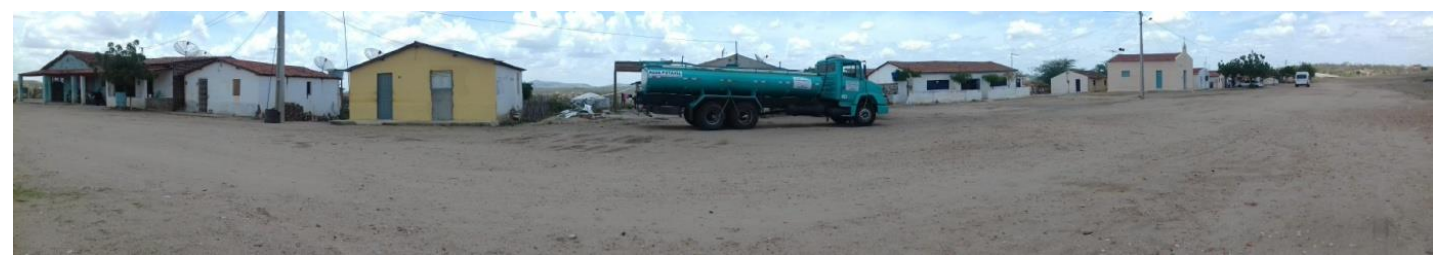

Figura 9- Caminhão pipa no município de Currais Novos.Fonte: Pesquisa de campo (2017).

Porém alguns entrevistados relataram que os programas do governo voltados a agricultura não têm sido eficazes, pois é dado uma solução errônea aos problemas de não produtividade das culturas. O programa do governo no qual se refere os agricultores é o programa de distribuição de sementes para agricultores familiares. Diante das condições ambientais do semiárido, o programa apresenta ineficiência, pois as sementes distribuídas para os agricultores não germinam, devido a escassez de água e ao manejo inadequado do solo. Um dos moradores relatou exatamente isso, em um trecho de sua entrevista, expondo o seguinte:

"Eu não sei tem algum programa do governo que ajuda as pessoas aqui, talvez tenha, não sei se esse ano veio àquele que dá as sementes para o agricultor plantar, no caso, esse programa não ajuda o agricultor, porque o problema aqui é a falta de chuva, eles podem até plantar essas sementes mais não vai prosperar". (Trecho da 
entrevista realizada no dia 20/02/2017 com o morador 06).

Entre os entrevistados parece haver um certo consenso em relação as mudanças do clima que têm sido resultantes de atividades humanas sobre a natureza, trazendo com isso impactos socioeconômicos e ambientais. A maioria dos impactos, na perspectiva de Nobre (2008), tem sido negativos e requerem políticas de mitigação e de adaptação, que foram instituídas pelo Plano Nacional de Adaptação em 2016, que prevê estratégias de adaptação para 11 setores.

Os impactos contribuem para que deixe comunidades rurais e moradores pobres, sobretudo, do semiárido norte-rio-grandense, vulneráveis ao acesso a água para o consumo e para o desenvolvimento de atividades agrícolas e de criatórios, tornando-se numa das maiores preocupações dos entrevistados. Cabe destacar que as mudanças climáticas têm sido percebidas pelos entrevistados como sendo o principal agente causador das dificuldades enfrentadas por eles. Contudo, muitos dos inquiridos não conseguem perceber e nem expressar que muitas das dificuldades vividas por eles resultam das suas próprias intervenções humanas, no qual o desmatamento da parca e rala cobertura da caatinga, predominante no semiárido norte-rio-grandense, vem se constituindo num dos maiores problemas a ser evitado e mitigado pelos sertanejos. Sabe-se na realidade, que o semiárido investigado não contribui, nas mesmas proporções que áreas urbanas e mais desenvolvidos do Estado, com a elevação das mudanças climáticas e a difusão de impactos decorrentes. Mas, não restam dúvidas, que em proporções menores as pessoas residentes nos municípios desta investigação têm um modo ou estilo de vida que tem contribuído para a mudança do clima e por ela são afetados diretamente com as secas permanentes (desde 2012 até os dias atuais), semiaridez, escassez de água, desertificação, principalmente.

\section{CONSIDERAÇÕES FINAIS}

Por meio deste trabalho constatou-se que as mudanças climáticas locais foram percebidas por sertanejos do semiárido do Rio Grande do Norte, a partir das alterações ambientais e dos impactos que ocorreram no município onde habitam. Porém, os sertanejos não relacionam a degradação ambiental, provocada muitas vezes pelas ações antrópicas, como um fator que vem contribuindo para a mudança do clima.

A principal queixa da população refere a escassez de água e a seca, que vêm impossibilitando a criação de animais, a pesca e a plantação de culturas, fatores esses que refletem diretamente na economia local, afetando não só as famílias que tem a agricultura com fonte de renda, mais também os comerciantes locais que sentem o reflexo da improdutividade nas lavouras diante da queda nas vendas de seus produtos, ocasionando um quadro de vulnerabilidade socioeconômica para a região.

Deve-se ressaltar que, apesar de toda a dificuldade que o sertanejo vem enfrentando, devido aos impactos associados às mudanças climáticas, a população que reside no semiárido não expressa o desejo de sair da região, e 
acreditam na possibilidade de melhorias em um futuro bem próximo, são motivados pela sua cultura, tradição e religiosidade.

Diante da grave situação de escassez de água, a população tem adotado diversas técnicas de mitigação e adaptação, como a captação de água da chuva e a abertura de poços. Essas técnicas são consideradas simples, mas, vêm contribuindo positivamente para que os sertanejos consigam conviver com a seca. Apesar da maior parte da população entrevistada afirmar que vem utilizando essas técnicas para minimizar e conviver com os impactos da seca, a porcentagem de sertanejos entrevistados que afirmam não fazer nada para minimizar esses impactos é considerada alta, tendo em vista a dificuldade que a população enfrenta para ter acesso a água. Isso demonstra uma falta de sensibilização por parte de alguns sertanejos, que mesmo diante da escassez de água nem mesmo racionam água, para garantir que esse recurso dure por mais tempo na região.

Por fim, pode-se afirmar que o problema das mudanças do clima só terá solução quando houver diretrizes ou procedimentos de participação ampla de governos, empresas e cidadãos comuns, cada um cumprindo a sua parte, demonstrando responsabilidade social e sustentabilidade. Ou seja, é importante a implementação de políticas públicas e novas tomadas de decisão, por parte dos gestores públicos e da própria sociedade em geral, em relação ao desenvolvimento de atividades econômicas que reduzam a emissão de gases do efeito estufa, mas sobretudo que proporcione a formação e a promoção de uma educação sobre mudanças climáticas, com estratégias de mitigação e de adaptação para a população local. Isso contribuirá para a sensibilização do uso mais eficiente e consciente dos recursos hídricos e para conservação da vegetação nativa. Isso evitará o desperdício de água, e, por conseguinte, contribuirá para a conservação dos recursos hídricos, para que nos períodos de secas severas a população não sofra tanto com a falta de água, a conservação da vegetação nativa reduzirá o desmatamento, o principal causador do aquecimento global e das mudanças climáticas.

É necessário, também, que as políticas públicas de convivência com a seca e com a vivência no semiárido, principalmente no Rio Grande do Norte, (como a difusão de tecnologias sociais de sistema de captação de água in situ) não sejam apenas voltadas para o simples acesso a água, mas, sobretudo, que englobem medidas mais eficientes e sustentáveis para a principal atividade econômica da região, que é a agricultura de subsistência, atividade secular ao torrão semiárido, no intuito de se reduzir a emissão de gases do efeito estufa e promover o desenvolvimento do homem sertanejo.

Nesse sentido, algumas estratégias para resgatar a produtividade da agricultura podem ser adotadas como práticas de manejo adequado do solo, com o uso de cobertura vegetal morta, que proporciona o aumento da infiltração de água no solo e diminui a perda de água por evaporação. Outra estratégia é o reuso de efluente tratado para a irrigação das culturas, através de sistemas de irrigação localizada. Essa prática permitirá que o solo receba uma grande carga de matéria orgânica, permitindo o crescimento das plantas, e não condiciona a irrigação ao período chuvoso, tornando as lavouras produtivas mesmo em períodos de seca.

Conclui-se que a mitigação e a adaptação dos sertanejos do semiárido do Rio Grande do Norte às mudanças climáticas envolvem questões complexas, de 
caráter ambiental, social e econômico, no qual a adoção de medidas mitigadoras visando melhorar os sumidouros de carbono, como é o caso da revegetação e de adaptação (respostas geoambientais de ajustes nos sistemas naturais e humanos, reduzindo danos e explorando oportunidades sustentáveis) necessitam ser implantadas o quanto antes para diminuir as vulnerabilidades socioambientais das populações mais frágeis e menos aquinhoadas. Precisa-se, com os resultados desta pesquisa, apresentar urgentemente diretrizes ou estratégias mitigadoras ou métodos ambientais mais sustentáveis, em cima das vulnerabilidades percebidas, com vistas a reduzir os efeitos perversos das mudanças do clima, muitas delas resultantes das próprias ações e atividades humanas mais impactantes.

\section{AGRADECIMENTOS}

Os autores agradecem ao Instituto Federal do Rio Grande do Norte (IFRN) e ao Conselho Nacional de Desenvolvimento Científico e Tecnológico (CNPq) pelas possibilidades dadas a realização da pesquisa, apoiando técnicofinanceiramente.

\section{REFERÊNCIAS}

ANDRADE, A. J. P. et.al. As percepções sobre as variações e mudanças climáticas e as estratégias de adaptação dos agricultores familiares do Seridó Potiguar. Revista Desenvolvimento e Meio Ambiente, Paraná, v. 31, p. 77-96, ago.2014.

BARBIERI. J. C. Meio ambiente e gestão ambiental. In: __. Gestão ambiental empresarial: conceitos, modelos e instrumentos. 2. Ed. São Paulo: Saraiva, 2007. p. 5-32.

BARDIN, L. Análise de conteúdo. Lisboa: Edições 70, 1977.

BERTONCINI, E. I. Tratamento de efluentes e reúso da água no meio agrícola. Revista Tecnologia e Inovação Agropecuária, São Paulo, v. 1, n. 2, p. 152-169, dez. 2008.

BRASIL. Conselho Nacional de Saúde. Resolução n 466, de 12 de dezembro de 2012. Aprova normas regulamentadoras de pesquisas envolvendo seres humanos. Brasília: Diário Oficial da União, 2013.

BRASIL. Mudanças climáticas para o semiárido brasileiro. Instituto Nacional do Semiárido. Campina Grande: INSA, 2013.

Secretaria de Políticas de Desenvolvimento Regional e Ministério da Integração Nacional. Nova delimitação do semiárido brasileiro. Brasília: Ministério da Integração Nacional,2005.

. Secretaria de Ciência, Tecnologia e Meio Ambiente de Pernambuco. O que os pernambucanos pensam sobre meio ambiente, sobre desenvolvimento e qualidade de vida. Pernambuco: Secretaria de Ciência, Tecnologia e Meio Ambiente de Pernambuco 2003.

Ministério do Meio Ambiente. Mudanças climáticas: caderno de debate.

em: 
http://www.mma.gov.br/estruturas/secex_cnma/_arquivos/caderno_de_debate. pdf. Acesso em: 25 jun. 2017.

. Delimitação do semiárido mantém formação atual e inclui 54 novos municípios. Disponível em: <http://www.integracao.gov.br/web/guest>. Acesso em: 15 ago. 2017.

CANTERO, J. G. El cambio climático en Europa: percepción e impactos 19502050. España. Los verdes-ALE/EQUO, 2015.

CARMO, L. R. Dinâmica demográfica e mudanças ambientais globais: novas vulnerabilidades. São Paulo: ABEP/UNICAMP, 2008.

CERVO, A. L.; BERVIAN, A. Metodologia científica. 5. ed. São Paulo: Prentice Hall, 2002.

FONTANELLA, B.J.B.et al. Amostragem por saturação em pesquisas qualitativas em saúde: contribuições teóricas. Caderno de Saúde Pública, Rio de Janeiro, v. 24, n. 1, p. 17-27, jan. 2008.

GIDDENS, A. The politics of climate change. Cambridge: Polity Press, 2009.

GIL, A.C. Métodos e técnicas de pesquisa social. São Paulo: Editora Atlas S.A., 2008.

IPCC. Intergovernmental Panel on Climate Change. WGII AR5 technical summary climate change 2014: impacts, adaptation, and vulnerability. EUA: IPCC, 2014.

KIDDER, L. H. Métodos de pesquisa nas relações sociais. São Paulo: EPU, 1987.

LÁZARO, A.; CABECINHAS, R.; CARVALHO, A. Percepções de risco e de responsabilidade face às alterações climáticas. In: C. Borrego, A.I. Miranda, E. Figueiredo, F. Martins, L. Arroja e T. Fidélis (Org.). Um futuro sustentável: ambiente, sociedade e desenvolvimento (Vol. 1, pp. 272-278). Aveiro: Universidade de Aveiro, 2007.

LEFF, E. Mudança climática, energia e desenvolvimento sustentável. In:

Discursos sustentáveis. São Paulo: Cortez, 2010. Cap. 9.

LIMANTOL, A M. et al. Farmers' perception and adaptation practicet o climate variability and change: a case study of the Vea catchment in Ghana. Springer Plus. 2016; 5:830.

MARENGO, J. A. et al. Caracterização do clima atual e definição das alterações climáticas para o território brasileiro ao longo do século XXI. Brasília: MMA,2007. Disponível em: $<$ http://mudancasclimaticas.cptec.inpe.br/ rmclima/pdfs/prod_probio/Sumario. pdf>. Acesso em: 10 set. 2016.

MINAYO, M. C. S. O desafio do conhecimento: pesquisa qualitativa em saúde. Rio de Janeiro: Hucitec, 1992.

NOBRE, C. A. Mudanças climáticas e o Brasil: contextualização, Parcerias Estratégicas, v. 13, n. 27, p. 7-18, 2008.

OLIVEIRA, L. Percepção ambiental. Revista Geografia e Pesquisa, Ourinhos, v.6, p. 56-72, jul. /dez, 2001. 
PATTON, M. Q. Qualitative research \& evaluation methods, 3rd edn. Sage Publications, Thousand Oaks, 2002.

RIO GRANDE DO NORTE. Empresa de Pesquisa Agropecuária do Rio Grande do Norte. Monitoramento pluviométrico: 2012 a 2017. Disponível em: <http://187.61.173.26/monitoramento/monitoramento.php>. Acesso em: 31 dez. 2017.

ROSA, L. G.; SILVA, M. M. P. Percepção ambiental de educandos de uma escola do ensino fundamental. In: SIMPÓSIO ÍTALO BRASILEIRO DE ENGENHARIA SANITÁRIA E AMBIENTAL, 6., 2002, Vitória. Anais... Vitória: ABES, 2002. p. 1-5. Disponível em: <http://www.bvsde.paho.org/bvsacd/sibesa6/ccxxxii.pdf>. Acesso em: 27 jun. 2017

SÁ, C. P. A construção do objeto de pesquisa em representações sociais. Rio de Janeiro: EdUERJ, 1998.

Secretaria de Ciência, Tecnologia e Meio Ambiente de Pernambuco (SECTMA). O que os pernambucanos pensam sobre meio ambiente, sobre desenvolvimento e qualidade de vida. 2003.

SILVA, W. M. Representações sociais e percepção ambiental: a balneabilidade de praias de São Luís e São José de Ribamar, Maranhão, Brasil. Revista Rosa dos Ventos, Caxias do Sul, v. 8. p. 405-418, out./dez. 2016. Disponível em: <http://dx.doi.org/10.18226/21789061.v8i4p405>. Acesso em: 27 jun. 2017.

VALLE, C. E. do. A gestão. In: Qualidade ambiental: o desafio de ser competitivo protegendo o meio ambiental. São Paulo: Pioneira, 1995. p. 39-44.

VASCO, A. P.; ZAKRZEVSKI, S. B. B. O estado da arte das pesquisas sobre percepção ambiental no Brasil. Perspectiva, Erechim. v. 34, n. 125, p. 17-28, mar. 2010. 